\title{
Enhancing Addictions Training Within the Core Competencies for General Psychiatry Residents
}

\author{
Justine W. Welsh ${ }^{1}$ (D) S Sandra M. DeJong ${ }^{2} \cdot$ Jeffrey DeVido $^{3} \cdot$ Ann C. Schwartz $^{1}$
}

Received: 13 February 2020 / Accepted: 11 June 2020 / Published online: 26 June 2020

(C) Academic Psychiatry 2020

Approximately 8.5 million adults have a co-occurring substance use and mental health disorder [1]. Among individuals with opioid use disorder, $64.3 \%$ have been found to have pastyear mental illness [2]. The recent Surgeon General's Report on Alcohol, Drugs, and Health highlights the need for increased access to care, implementation of evidence-based programs, and maximization of prevention efforts [3]. As physicians with expertise in both addictions and co-occurring disorders, psychiatrists are positioned to play a key role in offering tailored treatment to these individuals. Unfortunately, the number of psychiatric addictions experts nationally is insufficient to meet the training needs in residency programs [4], and the workforce need far exceeds the annual number of graduates from addiction psychiatry fellowships.

Despite the expectation for the next generation of general psychiatrists to provide treatment for individuals with substance use disorders (SUDs), current ACGME requirements for addictions training in psychiatry are rather undeveloped [5]. In 2016, the President-elect of the American Association of Directors of Psychiatric Residency Training (SD) tasked a group of addictions experts to delineate specific milestones, sub-competencies, and requirements that might guide general psychiatry training directors in optimizing addictions training in their programs. The composition of the taskforce is fully described in previous publications [6, 7]. This article focuses on expert consensus from the taskforce on core elements of psychiatric education and training necessary to provide a basic competence in treating patients with SUDs. Milestones are knowledge, skills, attitudes, and other attributes for each of

Justine W. Welsh

Justine.Welsh@Emory.edu

Emory University School of Medicine, Atlanta, GA, USA

Cambridge Health Alliance, Cambridge, MA, USA

3 University of California, San Francisco, CA, USA the Accreditation Council for Graduate Medical Education (ACGME) competencies organized in a developmental framework from less to more advanced [5]. The ACGME recognized that the implementation of the milestones would be an iterative process, and revision of the milestones would be beneficial and necessary going forward. Milestones 2.0 is undergoing revision, and its current draft provides the framework for this paper [8]. The four competencies (systems-based practice, practice-based learning and improvement, professionalism, interpersonal and communication skills) which have been "harmonized" across medical specialties [9] are discussed in the context of addictions training in psychiatry. The goal of the manuscript is to specify what to teach, how to teach it, and how best to assess trainees' level of competence within each of the four harmonized competencies.

\section{Competency-Based Education Guidelines in Addictions for General Psychiatry Residents}

\section{Systems-Based Practice (SBP)}

\section{SBP1: Patient Safety and Quality Improvement}

Substance use can precipitate a number of acute and chronic safety concerns. Common medical complications related to the use of substances, psychiatric emergencies including suicidality, and high-risk behaviors must be rapidly identified. Training in prevention of and screening techniques for substance use is imperative in residency programs. In prescribing medications with addictive potential, residents should be able to effectively communicate risks, how to mitigate them, and how to implement monitoring practices (e.g., use of urine drug screens, pill counts, lock boxes, and proper disposal of unused medications). They must be able to delineate the difference between physiologic dependence and addiction. The use of prescription drug monitoring systems to assess potential 
overprescribing of controlled substances and attention to highrisk medication combinations should also be demonstrated.

\section{SBP2: System Navigation for Patient-Centered Care}

Even as federal funds have increased and services expanded, systems often remain disconnected and challenging to navigate. Given the complexity of patients with addictive disorders, effective longitudinal care often requires linking different services and systems. Determination of treatment intensity and level of care for patients with addictive disorders requires knowledge of contributing factors such as medical complications related to substance use, co-occurring mental health conditions, readiness and motivation for treatment, as well as the patient's living environment and risk of continued substance use. Residents must recognize the unique impact of disparities in access to care for mental health and addictive disorders for those of different racial, ethnic, gender, age, and sexual orientation groups. Clinicians and trainees also have the opportunity to counsel patients, their families, and other healthcare providers about the utilization of community supports and services, such as self-help groups, harm reduction services, and preventative resources.

\section{SBP3: Physician Role in Healthcare Systems}

Legislative initiatives have shaped the delivery of SUD treatment. Residents should be familiar with laws of parity for SUD and feel comfortable advocating for patients with SUDs. Advocacy can also be performed through recognizing patients with SUDs and promoting ways to provide adequate screening and identification in general medical settings.

\section{Teaching Methods for Systems-Based Practice}

Teaching about addictions requires a longitudinal approach across a variety of educational and clinical settings using multiple pedagogic methods. Recommended teaching and assessment methods for the four harmonized competencies are summarized in Table 1.

If no formal addiction treatment rotation sites are available, consider field trips to learn about other addiction resources in the community (e.g., sober housing, therapeutic communities, opioid treatment programs ("methadone clinics"), syringe services programs, another institution's detoxification or addiction treatment specialty unit, court-mandated treatment clinics/diversion programs, physician health programs, or community recovery meetings). The American Society of Addiction Medicine (ASAM) Patient Placement Criteria can be used to teach about a structured approach to developing a longitudinal plan of care [10].

Didactic seminars offer one opportunity to discuss parity, carve-outs, private vs. public options of care, and the role of stigma within systems as they apply to addictions. Recent legislation impacting addiction-related treatment provides the framework for these discussions. Having residents advocate alongside faculty on the state and national level will help promote much-needed progress in reducing barriers and stigma. Residents can also be incentivized to join professional organizations that offer an infrastructure and forum in which to communicate about larger advocacy issues.

\section{Assessment of Systems-Based Practice}

Direct observation, simulation, retrospective chart review, and role-play can be helpful in assessing residents' understanding of the organization of care in each delivery setting and their ability to integrate the care of patients across settings. Selfassessment and multi-rater evaluations can help identify a trainee's strengths and vulnerabilities in navigating systemsbased practice.

\section{Practice-Based Learning and Improvement (PBLI)}

\section{PBLI1: Evidence-Based and Informed Practice}

Understanding how common myths and stigma may interfere with care while still using the evidence base for assessment and treatment of SUDs is essential in psychiatric residency education. Residents should be able to cite sentinel studies regarding pharmacotherapy, psychotherapy, and combined interventions for the treatment of specific SUDs, as well as expert guidelines. There are a number of FDA-approved medications for substance use disorders including opioid, alcohol, and tobacco use disorders. The use of these medications promotes recognition that addiction is a chronic brain disease, with available evidence-based treatment approaches.

\section{PBLI2: Reflective Practice and Commitment to Personal Growth}

Reflective practice provides the opportunity for residents to assess their own communication skills, medical knowledge, and decision-making and explore the influence of implicit bias, countertransference, and stigma. With supervision, residents should define their own learning goals and commit to achieving them in a lifelong learning model.

\section{Teaching Methods for Practice-Based Learning and Improvement}

Educators have numerous opportunities to model selfreflection and personal growth. They can offer and elicit reactions to challenging patient interactions in supervision and group discussion. A number of freely accessible online 
Table 1 Teaching and assessment methods for the harmonized competencies

Teaching methods

Assessment tools

SBP Harm reduction strategies and patient monitoring are best taught through experiential learning

- Equip trainees with readily available naloxone kits and demonstrate their use

- Engage in doctor-patient role-plays focusing on prevention and acute intervention

- Demonstrate how to check prescription drug monitoring websites and observe residents' practice

Residents should have exposure to different levels of care for patients with SUDs

- Conduct field trips to learn about other resources in the community and social determinants of addictions

- Use American Society of Addiction Medicine Patient Placement Criteria as a model for longitudinal treatment planning

Residents should understand parity, carve-outs, private vs. public options of care, and the role of stigma within systems

- Review recent legislation impacting addiction-related treatment

- Mental Health Parity and Addiction Equity Act (MHPAEA)

- Affordable Care Act (ACA)

- Comprehensive Addiction and Recovery Act (CARA)

- Substance Use-Disorder Prevention that Promotes Opioid Recovery and Treatment for Patients and Communities Act (SUPPORT)

- Twenty-First Century Cures Act

- Have residents advocate alongside faculty on the state and national level

- Incentivize joining addiction-related professional organizations

- Offer clubs or other forums in which to communicate about larger advocacy issues

PBLI Online resources offer evidence-based guidelines for addiction treatment (see Table $2 \cdot$ Recorded sessions of brief interventions for curriculum resources)

- Multisource evaluations $\left(360^{\circ}\right.$ Assessments)

- Watch online archived webinars

- Host small group collaboratives to discuss guidelines

- Develop formal mentorship opportunities through Provider Clinical Support System and American Academy of Addiction Psychiatry

Educators should model self-reflection and personal growth

- Use case conferences to discuss challenging patients

- Share "lessons learned" from previous encounters that did not go as planned

PROF Faculty modeling is critical in teaching key skills and knowledge

- Demonstrate self-care

- Set reasonable treatment goals

- Process difficult encounters as a treatment team

- Peer support groups

Participation in national organizations provides access to mentorship and other resources

- American Academy of Addiction Psychiatry (AAAP)

- American Society of Addiction Medicine (ASAM)

- American Psychiatric Association (APA)

- Direct observation

- Simulation with standardized patients

- Role-play with colleagues and staff

- Retrospective chart review

- Self-assessment

- Multisource evaluations $\left(360^{\circ}\right.$ Assessments)

ICS Humanizing addictions through profiles of those struggling with SUDs can help address stigma

- Watch patient videotapes

- Invite patients and family members to speak in seminars

- Attend community-based treatment groups

Read or listen to the experiences of physicians who are in recovery

Documentation skills and ethics may need to be explicitly taught

- Review verbal and nonverbal communication skills by analyzing videotapes of clinical sessions

- Teach about confidentiality of patient records using case examples

- Practice communicating with patients and their families about limits of confidentiality using role-play

$S B P$ systems-based practice, $P B L I$ practice-based learning and improvement, $P R O F$ professionalism, ICS interpersonal and communication skills

resources offer evidence-based guidelines for addiction treatment that can also be incorporated into clinical and didactic sessions, including archived webinars, small group collaboratives, and formal mentorship opportunities for those interested in longitudinal learning (see Table 2 for curriculum resources).
- Multisource evaluations (360 ${ }^{\circ}$ Assessments)

- Observed interviews, e.g., Clinical Skills Verification Examinations

AAMC's MedEdPORTAL provides instruments to assess professionalism, including:

- The Professionalism Mini-Evaluation Exercise (P-MEX)

- Schwartz Values Survey

- Cultural Attitudes Survey

- Reflective essays, e.g., processing difficult encounters

- Direct observation

- Reflective essays

- Evaluation of videotaped sessions

- Simulation with standardized patients

- Case-based discussions

- Supervisor evaluations

Multisource evaluations ( $360^{\circ}$ Assessments) 
Table 2 Curriculum resources for addiction psychiatry

Resource/URL

\section{Curated resources}

National Institute on Drug Abuse (NIDA)

https://www.drugabuse.gov

National Institute on Alcohol Abuse and

$$
\text { Alcoholism (NIAAA) }
$$

www.niaaa.nih.gov

Substance Abuse and Mental Health Services

Administration (SAMHSA)

https://www.samhsa.gov/sbirt

American Academy of Addiction Psychiatry

(AAAP)

https://www.aaap.org/clinicians/area-resources/

https://www.aaap.

org/clinicians/education-training/

https://smiadviser.org/about/aaap?utm_source=

Partner_Page\&utm_medium $=$ AAAP

American Psychiatric Association (APA)

a) https://www.psychiatry.org/psychiatrists/
Contents

Patient information, reference materials

Patient information, provider training, screening, brief intervention and referral to treatment (SBIRT) materials

Patient information, reference materials

Cautions

Access

Open

Open

Open

Free online resources. Highlights content on substance use disorders in individuals with serious mental illness

Open practice/professional-interests/addiction-psychiatry

b) https://psychiatryonline.org/doi/pdf/10.1176/appi. books. 9781615371969
Open; specific content for purchase

American Medical Association (AMA)

https://www.ama-assn.org/delivering-

care/reversing-opioid-epidemic

American Society of Addiction Medicine (ASAM) E-learning modules, presentations, local chapters \&

https://elearning.asam.org/

https://www.asam.org/education/resources

California Society of Addiction Medicine (CSAM) Information on addiction medicine conferences, articles, www.csam-asam.org

www.csam-asam.org/resources

Alcohol Medical Scholar Program (AMSP)

www.alcoholmedicalscholars.org

Provider Clinical Support System (PCSS)

https://pcssnow.org/medication-assisted-treatment/ waiver-training-for-physicians/

https://pcssnow.org/mentoring/

Opioid Response Network State Targeted

Response - Technical Assistance (STR-TA)

https://opioidresponsenetwork.org/

Hazelden Professionals in Residency Program

https://www.hazeldenbettyford.

org/education/medical-

professional-education/professionals-residence

Opioid Overdose Prevention Toolkit

Store.samhsa.gov/product/opioid-overdoseprevention-toolkit/SMA18-4742

Project ECHO

https://echo.unm.edu/

https://echo.unm.edu/collaboratives/opioid

VA Guidelines on Treatment of Substance Use Disorders

https://www.healthquality.va. gov/guidelines/MH/sud/ speakers' bureaus

Primer on the opioid morbidity and mortality crisis guidelines, instructional videos

Slide decks on topics related to SUDs, including diagnosis, treatment, co-occurring disorders

Webinars, free buprenorphine waiver training, mentoring program

Referral platform for training and technical assistance from local expert consultants; Provides states and committees with help in expanding SUD treatment into systems and practices

Intensive training experience for trainees and/or faculty

Comprehensive document about opioid overdose; applicable to patients, families, first

Educational networks led by expert teams who use multi-point videoconferencing to conduct virtual clinics with community providers

Comprehensive document outlining VA guidelines for clinical care of SUD a) Primarily links to

other organizations' content

b) Detailed APA practice guidelines for pharm treatment of alcohol use disorders
Open

Open; specific content for purchase Open

Open

Open

Open

Purchase

Open

Open

Open 
Table 2 (continued)

\begin{tabular}{|c|c|c|c|}
\hline Resource/URL & Contents & Cautions & Access \\
\hline $\begin{array}{l}\text { California Healthcare Foundation } \\
\text { https://www.chcf.org/collection/webinar-series- } \\
\text { support-hospital- } \\
\text { opioid-use-treatment-project-shout/ }\end{array}$ & $\begin{array}{l}\text { Webinar series on topics related to starting patients on } \\
\text { agonist treatment while inpatient }\end{array}$ & & Open \\
\hline $\begin{array}{l}\text { Erowid } \\
\text { https://www.erowid.org/ }\end{array}$ & Glossary, user experiences, drug information & $\begin{array}{l}\text { Advocacy of } \\
\text { substance use }\end{array}$ & Open \\
\hline $\begin{array}{l}\text { SlideShare } \\
\text { https://www.slideshare.net/search/slideshow? } \\
\text { searchfrom=header\&q=addiction+psychiatry } \\
\text { Organized curricula }\end{array}$ & Various topics & $\begin{array}{l}\text { Variable quality and } \\
\text { reliability of } \\
\text { content }\end{array}$ & Open \\
\hline $\begin{array}{l}\text { MedEd PORTAL } \\
\text { https://www.mededportal.org/collections/ }\end{array}$ & $\begin{array}{l}\text { Structured curricula including teaching motivational } \\
\text { interviewing to residents; Clinical assessment of SUDs, } \\
\text { etc. }\end{array}$ & $\begin{array}{l}\text { Primary } \\
\text { care/non-- } \\
\text { psychiatrist focus }\end{array}$ & $\begin{array}{l}\text { Registration } \\
\text { required }\end{array}$ \\
\hline $\begin{array}{l}\text { American Association of Directors of Psychiatric } \\
\text { Residency Training (AADPRT) Virtual Training } \\
\text { Office } \\
\text { https://portal.aadprt.org/user/vto/category/563 }\end{array}$ & $\begin{array}{l}\text { Model curricula outlines for alcohol use disorder; } \\
\text { Addiction Training }\end{array}$ & & $\begin{array}{l}\text { Membership } \\
\text { required }\end{array}$ \\
\hline $\begin{array}{l}\text { Coalition on Physician Education in Substance Use } \\
\text { Disorders (COPE) } \\
\text { www.copenow.org }\end{array}$ & Primary care-oriented addictions curricula & & Open \\
\hline $\begin{array}{l}\text { Providers Clinical Support System for Medication } \\
\text { Assisted Treatment } \\
\text { (PCSS) http://pcssNOW.org/ }\end{array}$ & $\begin{array}{l}\text { Online curriculum modules, videos, virtual mentoring, } \\
\text { sample forms }\end{array}$ & & Open \\
\hline $\begin{array}{l}\text { Association of Directors of Medical School } \\
\text { Education in Psychiatry (ADMSEP) } \\
\text { http://www.admsep.org/csi-emodules.php }\end{array}$ & E-learning modules on psychiatric disorders & $\begin{array}{l}\text { No specific addiction } \\
\text { resources }\end{array}$ & Open \\
\hline $\begin{array}{l}\text { National Neuroscience Curriculum Initiative } \\
\text { (NNCI) } \\
\text { http://www.nncionline.org/ }\end{array}$ & Curricula, lesson plans, video resources & & $\begin{array}{l}\text { Registration } \\
\text { required }\end{array}$ \\
\hline $\begin{array}{l}\text { Rx for Change } \\
\mathrm{http}: / / \text { rxforchange.ucsf.edu/ }\end{array}$ & Psychiatrically oriented smoking cessation curriculum & & $\begin{array}{l}\text { Registration } \\
\text { required }\end{array}$ \\
\hline $\begin{array}{l}\text { MGH/McLean 4-year curriculum } \\
\text { https://www.ncbi.nlm.nih.gov/pmc/articles/ } \\
\text { PMC2898176/ }\end{array}$ & Published substance use curriculum & & Published \\
\hline
\end{tabular}

\section{Assessment of Practice-Based Learning and Improvement}

Residents are expected to demonstrate an ongoing effort to evaluate their clinical care practices, apply evidence-based practices, and commit to lifelong learning and personal growth. Supervisors can encourage or require trainees to video record problem-focused clips of clinical sessions for review one on one with supervisors or a peer group. If residents are working in treatment team models such as a detoxification unit, multisource assessments can rate their interactions with patients and staff regarding their ability to maintain an empathic stance.

\section{Professionalism (PROF)}

\section{PROF1: Professional Behavior and Ethical Principles}

Respecting patients and their autonomy are critical in treating this stigmatized population. Additional professional attitudes and behaviors include ensuring proper informed consent, commitment to patients' confidentiality, awareness and disclosure of conflicts of interest, and respect for differing values and worldviews. Concepts like compassion, caring, empathy, awareness of diversity, and intellectual and cultural humility are essential in working with patients with SUDs and must be modeled by teaching faculty.

\section{PROF2: Accountability/Conscientiousness}

A critical goal of residency training remains engendering a sense of accountability and responsibility for ensuring that care transitions and workflow impediments are handled effectively.

\section{PROF3: Well-Being}

Prevention of burnout and promotion of well-being have become critical elements of psychiatry residency training; for 
residents working in addictions, particular attention to factors that may cause burnout (e.g., the relapsing/remitting disease course, lack of resources and supervision, and turnover in staff), is needed.

\section{PROF4: Professional Identify and Development}

Given the shortage of psychiatrists with addictions expertise, developing leaders and experts within general psychiatry will be essential in meeting the residency training needs regarding addictions. Residency programs will need to engage in faculty development to identify and foster potential departmental champions and other potential role models to cultivate residents' development into addiction education leaders.

\section{Teaching Methods for Professionalism}

Recommendations for self-care, setting reasonable treatment goals, processing difficult encounters as a treatment team, and maintaining therapeutic optimism should be discussed and modeled by teaching faculty. Positive attitudes toward patients and patient care, exposure to a wide range of acuity including patients in long-term recovery, and working within an interdisciplinary team can inspire residents to explore a career in this area. Encouraging trainees to receive direct mentorship through psychiatric- and addiction-related organizations or availing themselves of other resources such as those provided by the Provider Clinical Support System (PCSS) can assist in developing future leaders in the field [11].

\section{Assessment of Professionalism}

Multisource evaluation ( $360^{\circ}$ Assessments) can be an effective tool for providing feedback regarding professionalism to trainees. Observed interviews offer an opportunity for supervisors to provide feedback on interactions with patients with SUDs and address transferential or other psychological factors that may result in unprofessional attitudes and behaviors. A number of useful instruments to assess professionalism are freely available online (see Table 1).

\section{Interpersonal and Communication Skills (ICS)}

\section{ICS1: Patient- and Family-Centered Communication}

Developing skills in motivational interviewing, a core evidence-based approach, is vital early on in training and involves learning to engage in shared decision-making at the appropriate motivational level. Communicating with families in the treatment of patients with SUDs, particularly with transitional-age and geriatric patients, can be key; however, such communication must be handled sensitively and with respect for the autonomy of the patient, including a clear discussion of limits of confidentiality.

\section{ICS2: Interprofessional and Team Communication}

Treating patients with addictions is often team based, involving non-psychiatrist clinicians such as primary care physicians, emergency room physicians, nurses, and other mental health professionals. The various team members may have different approaches to care, values and ethics, opinions about appropriate treatment, and familiarity with medical and psychiatric terminology. As team leaders, psychiatrists need to effectively and inclusively communicate with all team members and model optimal communication style and practices.

\section{ICS3: Communication Within Healthcare Systems}

Documentation of clinical sessions in addictions treatment should be accurate, thorough, and concise and outline the clinical reasoning and supporting evidence that lead logically to the treatment plan. The SAMHSA SUD stigma webinar [12] can be a helpful aid in reflecting upon documentation practices. Content included on emails and through portals should be sensitively handled and, in some cases, communicated by telephone or in person.

States and regions vary regarding practice, involuntary treatment, health regulations, psychiatric forensic evaluations, mandated prescription monitoring program participation, and physician health programs. Residents need to learn how to communicate about these regional variations, as well as apply federal laws including HIPAA confidentiality and practice of privacy standards and Confidentiality of Alcohol and Drug Abuse Patient Records, 42 Code of Federal Regulations 2 (“42 CFR Part 2", SAMSHA.gov) [13].

\section{Teaching Methods for Interpersonal and Communication Skills}

Watching patient videotapes, inviting patients and family members to speak in seminars, attending community-based treatment groups such as Narcotics Anonymous (NA) and Alcoholics Anonymous (AA), and having physicians share their own struggles with addictions may be helpful in addressing the stigma of SUDs (for videos of patients' experience of addictions, see https://www.aaap.org/clinicians/educationtraining/patient-videos/). These skills may be taught in didactics on documentation and ethics.

Teaching practical tips and motivational interviewing skills can help reduce residents' hesitation and address patients' ambivalence to treatment. For example, clinicians can be equipped with readily available naloxone kits and easy-toread handouts for demonstrations. Doctor-patient role-plays offer a way to practice unfamiliar and sometimes 
uncomfortable conversations including techniques to reduce exposure to communicable diseases. Having supervisors review residents' documentation of patient encounters to provide formative feedback is critical. A retrospective chart review can provide formal written feedback.

\section{Assessment of Interpersonal and Communication Skills}

Assessing a resident's competence in communicating effectively with patients with SUDs is best achieved by direct observation. Review of videotaped sessions allows for selfreflection and close observation of process details, including nonverbal cues, that may impair alliance development and communication. Standardized patients or structured case discussions allow for honing in on particularly challenging issues, such as the highly ambivalent patient. Skills can also be effectively assessed as part of routine supervision and precepting as well as rotation evaluations, in multisource evaluation $\left(360^{\circ}\right.$ Assessments) that include patient input, and, particularly for documentation, through retrospective chart reviews.

\section{Discussion}

The development of a skilled workforce to teach and practice addiction psychiatry is imperative in addressing the nation's substance use crisis. Unfortunately, training barriers that have prevented educational experiences in addiction include lack of buprenorphine-waivered physicians, faculty with addiction expertise, access to different levels of care for rotation sites, as well as the time and effort needed to change pre-existing rotation schedules [14]. The knowledge necessary to build these skills likely cannot be obtained by the standard 1month rotation block offered by many programs.

As a resource to reduce the burden of creating new educational content, members of the Addictions Taskforce pooled existing resources together and created a table of curricular resources for addictions teaching and training (see Table 2). For faculty, online CME is also offered through a number of organizations, including PCSS and ASAM. Project ECHO is an additional model that provides expertise remotely to increase the level of provider comfort in seeing patients with addictions to provide learning opportunities for residents [15]. Exposing residents to patients in different stages of recovery in longitudinal settings can help reduce transference and implicit bias that may develop without the appreciation that patients can improve over time and with treatment.

Using a competence-based approach to define, teach, and assess sub-competencies and milestones for the general resident treating patients with addictions may better equip the psychiatric workforce of the future.
Acknowledgments The authors would like to thank the members of the AADPRT Addictions Taskforce for their contributions to this piece including Richard Camino-Gaztambide, Ray Hsiao, Scott Oakman, John Renner, Andrew Saxon, Jeremy Kidd, Ramzi Mardam Bey, Kelly Blankenship, Amber Frank, Surita Rao, Cathryn Galanter, Bill Haning, Kenneth Zoucha, Daniela Rakoceivc, and Kevin Gray. The authors would also like to recognize the contribution of Scott Oakman and Amber Frank for compiling educational resources.

\section{Compliance with Ethical Standards}

Disclosures Dr. Welsh has received consulting fees from Analgesic Solutions and training fees from Chestnut Health Systems. Dr. Welsh is a consultant to the Addictions Taskforce.

Dr. Schwartz is the chair of the AADPRT Addictions Taskforce and is a member of the Academic Psychiatry Editorial Board. Dr. DeJong was President of AADPRT 2017-18 and established the Addictions Taskforce.

\section{References}

1. Substance Abuse and Mental Health Services Administration. Results from the 2017 National Survey on drug use and health: detailed tables, SAMHSA, CBHSQ. United States Department of Health and Human Services; 2018. Available from: https://www. samhsa.gov/data/sites/default/files/cbhsq-reports/ NSDUHDetailedTabs2017/NSDUHDetailedTabs2017.htm\# lotsect1pe. Accessed 2 Jan 2019.

2. Jones CM, McCance-Katz EF. Co-occurring substance use and mental disorders among adults with opioid use disorder. Drug Alcohol Depend. 2019;197:78-82.

3. Substance Abuse and Mental Health Services Administration (US), Office of the Surgeon General (US). Facing addiction in America: the surgeon general's report on alcohol, drugs, and health. Washington (DC): US Department of Health and Human Services; 2016. Available from: http://www.ncbi.nlm.nih.gov/ books/NBK424857/. Accessed 6 Aug 2019.

4. Madras BK, Connery H. Psychiatry and the opioid overdose crisis. FOC. 2019;17:128-33.

5. ACGME Program requirements for graduate medical education in psychiatry; 2019. Available from: https://www.acgme.org/Portals/ 0/PFAssets/ProgramRequirements/400_Psychiatry_2019.pdf?ver= 2019-06-19-091051-927. Accessed 23 Aug 2019.

6. Schwartz AC, Frank A, Welsh JW, Blankenship K, DeJong SM. Addictions training in general psychiatry training programs: current gaps and barriers. Acad Psychiatry. 2018;42:642-7.

7. Welsh JW, Schwartz AC, DeJong SM. Addictions training in child and adolescent psychiatry fellowships. Acad Psychiatry. 2019;43: 13-7.

8. Edgar L, Roberts S, Holmboe E. Milestones 2.0: A Step Forward. J Grad Med Educ. 2018;10:367-9.

9. Edgar L, Roberts S, Yaghmour NA, Leep Hunderfund A, Hamstra SJ, Conforti L, et al. Competency crosswalk: a multispecialty review of the Accreditation Council for Graduate Medical Education milestones across four competency domains. Acad Med. 2018;93: 1035-41.

10. Mee-Lee D. The ASAM criteria: treatment criteria for addictive, substance-related, and co-occurring conditions. The Change Companies: Carson City; 2013.

11. Home - providers clinical support system: resources for PCPs. Providers Clinical Support System. Available from: https:// pcssnow.org/. Accessed 23 Aug 2019. 
12. krista.trovato. The power of perceptions and understanding; 2018. Available from: https://www.samhsa.gov/power-perceptionsunderstanding. Accessed 13 Aug 2019.

13. Confidentiality of substance use disorder patient records [Internet]. Federal Register; 2017. Available from: https://www. federalregister.gov/documents/2017/01/18/2017-00719/ confidentiality-of-substance-use-disorder-patient-records. Accessed 13 Aug 2019.

14. Renner JA. Counteracting the effect of stigma on education for substance use disorders. FOC. 2019;17:134 40.
15. Komaromy M, Duhigg D, Metcalf A, Carlson C, Kalishman S, Hayes L, et al. Project ECHO (Extension for Community Healthcare Outcomes): a new model for educating primary care providers about treatment of substance use disorders. Subst Abus. 2016;37:20-4.

Publisher's Note Springer Nature remains neutral with regard to jurisdictional claims in published maps and institutional affiliations. 